\title{
Bioesai bioinsektisida Beauveria bassiana dari Sumatera Selatan terhadap kutu putih pepaya, Paracoccus marginatus Williams \& Granara De Willink (Hemiptera: Pseudococcidae)
}

\author{
Bioessay of Beauveria bassiana from South Sumatra against \\ the papaya mealybug, Paracoccus marginatus Williams \& Granara De \\ Willink (Hemiptera: Pseudococcidae) \\ Siti Herlinda ${ }^{1,2 *}$, Komang Agus Darmawan², Firmansyah², Triani Adam², \\ Chandra Irsan ${ }^{2}$, Rosdah Thalib ${ }^{1,2}$ \\ ${ }^{1}$ Pusat Unggulan Riset Pengembangan Lahan Suboptimal, Universitas Sriwijaya \\ Jalan Padang Selasa 524, Palembang 30139 \\ ${ }^{2}$ Jurusan Hama dan Penyakit Tumbuhan, Fakultas Pertanian, Universitas Sriwijaya, \\ Jalan Raya Palembang-Prabumulih, Km. 32, Ogan Ilir, Indralaya 30662
}

(diterima Mei 2012, disetujui Agustus 2012)

\begin{abstract}
ABSTRAK
Kutu putih pepaya, Paracoccus marginatus (Hemiptera: Pseudococcidae) di lahan rawa lebak Sumatera Selatan, dapat menyebabkan banyak tanaman pepaya muda yang mati dan kualitas buah menurun. Penelitian ini bertujuan untuk menguji bioesai formulasi Beauveria bassiana terhadap nimfa $P$. marginatus. B. bassiana diperbanyak pada media beras. Bahan pembawa yang digunakan adalah kompos, kompos kering, abu sekam, dedak, serbuk kayu, dedak dicampur dengan serbuk kayu, kompos diperkaya dengan Trichoderma virens. Kontrol yang digunakan ada dua macam, yaitu air steril (kontrol 1) dan isolat B. bassiana (kontrol 2). Viabilitas konidia B. bassiana pada kontrol 2 tertinggi $(46,33 \%)$ dibandingkan dengan perlakuan lain. Viabilitas konidia kontrol 2 tersebut tidak berbeda nyata dengan formulasi dengan bahan pembawa dedak, dedak campuran serbuk kayu, dan kompos diperkaya $T$. virens. Mortalitas nimfa $P$. marginatus tertinggi $(82,86 \%)$ terjadi pada formulasi dengan bahan pembawa kompos diperkaya dengan $T$. virens dan berbeda nyata dibandingkan dengan perlakuan lainnya. Mortalitas nimfa terendah $(73,48 \%)$ terjadi pada formulasi abu sekam dan berbeda nyata dibandingkan dengan perlakuan lainnya. Mortalitas kontrol ratarata $29,52 \%$ pada kontrol 1, sedangkan pada kontrol 2 rata-rata $75,71 \%$. Median lethal time $\left(\mathrm{LT}_{50}\right)$ tersingkat (3,55 hari) ditemukan pada formulasi kompos diperkaya dengan $T$. virens, sedangkan terlama (3,73 hari) ditemukan pada formulasi abu sekam. Dengan demikian, bioinsektisida yang paling efektif adalah formulasi kompos diperkaya dengan $T$. virens.
\end{abstract}

Kata kunci: bioinsektisida, Beauveria bassiana, Paracoccus marginatus

\begin{abstract}
In fresh swamp areas of South Sumatra, papaya mealybug, Paracoccus marginatus (Hemiptera: Pseudococcidae) could cause severe damage to young papaya trees and decreased the fruit quality. The objective of this research was to bioassay test of the bioinsecticide Beauveria bassiana againts nymphs of $P$. marginatus. B. bassiana was conducted on rice medium. The bioinsecticide was formulated using dried compost, compost gram, paddy ash, paddy bran, woody powder, paddy bran mixed with woody powder, compost enriched with Trichoderma virens. Controls used were
\end{abstract}

\footnotetext{
*Penulis korespondensi: Siti Herlinda. Jurusan Hama dan Penyakit Tumbuhan, Fakultas Pertanian, Universitas Sriwijaya, 
sterile water (control 1) and isolate of B. bassiana (control 2). Results showed that conidial viability of $B$. bassiana on control 2 was the highest $(46.33 \%)$. The viability of control 2 was not significantly different from the formulations with carrier of the paddy bran, the paddy bran mixed with woody powder, and the compost enriched with $T$. virens. The highest nymph mortality $(82.86 \%)$ was found on formulation of compost enriched with $T$. virens and was significantly different from other treatments. The lowest visibly (73.48\%) occured on formulation of paddy ash, and was significantly different from other treatments. Mortality on control 1 on average was $29.52 \%$, whereas control 2 averaged of $75.71 \%$. The shortest median lethal time $\left(\mathrm{LT}_{50}\right)(3.55$ days $)$ was found on formulation of compost enriched with $T$. virens but the longest one (3.73 days) occured on the formulation of paddy ash. Overall, the most effective bioinsecticide was the formulation of compost enriched with T. virens.

Key words: bioinsecticide, Beauveria bassiana, Paracoccus marginatus

\section{PENDAHULUAN}

Pepaya di ekosistem lebak Sumatera Selatan merupakan buah-buahan yang cukup banyak dibudidayakan, namun produktivitasnya masih rendah karena banyak kendala yang dihadapi. Kendala utama saat ini adalah serangan hama pendatang baru, yaitu kutu putih pepaya, Paracoccus marginatus Williams and Granara de Willink (Hemiptera: Pseudococcidae). Hama baru ini berasal dari benua Amerika dan masuk ke Indonesia tahun 2008 (Rauf 2009). Serangga hama ini awalnya ditemukan di Kebun Raya Bogor, Jawa Barat yang menyerang buah, batang, dan daun pepaya sehingga menyebabkan ribuan pohon pepaya menurun produktivitasnya (Friamsa 2009). Saat ini P. marginatus telah ditemukan menyerang pepaya di Sumatera Selatan.

Alternatif pengendalian yang lebih aman baik bagi produk maupun lingkungan sekitarnya perlu dilakukan untuk mengatasi permasalahan hama ini. Karena produk buah pepaya dikonsumsi segar, maka produk dituntut bebas dari residu racun. Pengendalian hayati adalah salah satu alternatif pengendalian hama pepaya ini. Pengendalian hayati dengan memanfaatkan cendawan entomopatogen berpotensi untuk dikembangkan. Jenis cendawan entomopatogen yang telah ditemukan di ekosistem rawa lebak Sumatera Selatan adalah Beauveria bassiana (Herlinda et al. 2006a; Herlinda 2010), dan Metarhizium anisopliae (Herlinda et al. 2008a, b; Herlinda et al. 2010). Cendawan ini terbukti cukup efektif membunuh serangga hama dari ordo Hemiptera (Herlinda et al. 2006a) dan Lepidoptera (Nunilahwati et al. 2012). Metarhizium juga efektif mematikan telur dan larva Spodoptera litura (Trizelia et al. 2011). Selain itu, cendawan lainnya yang dimanfaatkan untuk pengendalian serangga hama adalah Nomuraea rileyi (Trizelia 2008). Dalam pemanfaatan cendawan ini perlu perlu upaya untuk mempertahankan keefektifan dan persistensinya melalui pengembangan formulasinya. Keefektifan dan persistensi formulasi dipengaruhi media perbanyakan, carrier (bahan pembawa), dan konidia cendawannya (Feng et al. 1994). Penelitian ini bertujuan untuk melakukan bioesai bioinsektisida dari $B$. bassiana terhadap nimfa kutu putih pepaya, $P$. marginatus.

\section{BAHAN DAN METODE}

Penelitian ini dilaksanakan di Laboratorium Entomologi, Jurusan Hama dan Penyakit Tumbuhan, Fakultas Pertanian, Universitas Sriwijaya sejak Januari hingga Agustus 2011. Suhu dan kelembaban nisbi selama penelitian ratarata ialah $28,25^{\circ} \mathrm{C}$ dan $80,18 \%$. Penelitian ini menggunakan Rancangan Acak Lengkap (RAL) dengan sembilan perlakuan dan 10 ulangan. $B$. bassiana yang diperbanyak pada media beras, lalu dibuatkan variasi formulasinya. Bahan pembawa yang digunakan untuk formulasi tersebut adalah kompos, kompos kering, abu sekam, dedak, serbuk kayu, dedak dicampur dengan serbuk kayu, kompos diperkaya dengan Trichoderma virens. Kontrol yang digunakan ada dua macam, yaitu air steril (kontrol 1) dan isolat B. bassiana (kontrol 2).

\section{Pembuatan bioinsektisida}

Isolat $B$. bassiana (BPcMS) yang digunakan dalam pengujian ini diisolasi dari larva Pseudoplusia chalcites (Esper) (Lepidoptera: Noctuidae) dari tanaman wortel di Muarasiban, Pagaralam. Isolat diperbanyak pada media glucose 
yeast agar (GYA) $(250 \mathrm{ml}$ aquades, $1 \mathrm{~g}$ yeast, $5 \mathrm{~g}$ agar-agar, 1,3 $\mathrm{g}$ tepung jangkrik dan 2,5 $\mathrm{g}$ glukosa). Penambahan tepung jangkrik dilakukan sebelum media disterilisasi dengan autoklaf, lalu ditambahkan antibiotik. Kemudian, media diinokulasikan cendawan dan diinkubasikan selama 10 hari pada suhu kamar.

Isolat murni $B$. bassiana diperbanyak dalam media beras (Gambar 1). Beras sebanyak $5 \mathrm{~kg}$ direndam dalam larutan ekstrak kompos kulit udang (EKKU) 20\% (1300 $\mathrm{ml}$ air dan $200 \mathrm{ml}$ EKKU) selama kurang lebih satu jam, lalu dimasukkan ke dalam kantung plastik tahan panas sebanyak $100 \mathrm{~g}$. EKKU dibuat dari fermentasi tepung kulit udang yang pembuatannya mengikuti metode Suwandi (2004). Beras tersebut disterilkan di dalam autoklaf selama satu jam. Setelah media uji beras tersebut diinokulasi $B$. bassiana, kemudian diinkubasi selama 10 hari hingga terbentuk konidia.

Bahan pembawa yang digunakan adalah kompos, kompos kering, abu sekam, dedak, serbuk kayu, dedak dicampur dengan serbuk kayu, kompos diperkaya dengan Trichoderma virens. Kompos kering adalah kompos yang dijemur selama 8 jam hingga kadar air berkisar $20 \%$. Untuk kompos yang tidak dijemur dan kompos yang diperkaya $T$. virens hanya dilakukan pengayakan agar kotoran lain seperti batuan dan sampah tidak terbawa. Bahan pembawa, dedak, abu sekam, dan serbuk kayu disterilkan di dalam oven selama 3 jam pada suhu $100^{\circ} \mathrm{C}$ hingga kadar air yang didapat pada bahan tersebut menjadi $20 \%$. Bahan pembawa selanjutnya ditimbang sebanyak $700 \mathrm{~g}$ dan ditambahkan inokulum $B$. bassiana dari biakan medium beras sebanyak $300 \mathrm{~g}$ dan dicampur rata membentuk suatu formulasi. Bioinsektisida yang telah diformulasikan (Gambar 2) diinkubasi selama satu bulan sebelum diujicobakan.

\section{Persiapan serangga uji}

Serangga uji yang digunakan adalah nimfa instar ketiga hama kutu putih pepaya yang awalnnya diambil dari perkebunan petani yang tidak mengaplikasikan pestisida sintetik dan diperbanyak di laboratorium. Lokasi pengambilan serangga ini di daerah ekosistem Rawa Lebak di Desa Tanjung Pering Indralaya. Lalu, serangga dibawa ke laboratorium untuk dibiakkan hingga mencapai generasi kedua pada tanaman pepaya umur 1 bulan.

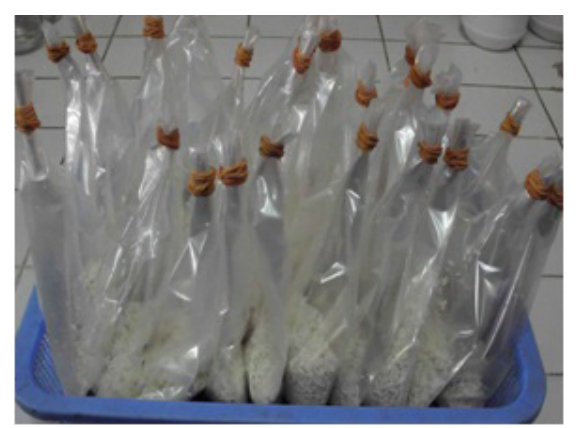

Gambar 1. Beauveria bassiana pada media beras.

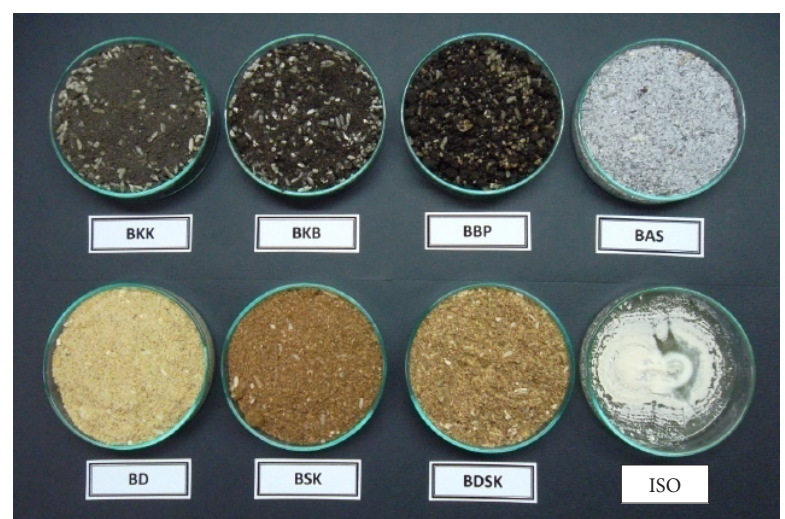

Gambar 2. Beauveria bassiana yang diformulasikan dengan bahan pembawa kompos kering (BKK), kompos (BKB), kompos diperkaya dengan Trichoderma virens (BBP) abu sekam (BAS), dedak (BD), serbuk kayu (BSK), dedak dicampur dengan serbuk kayu (BDSK), dan isolat (ISO).

\section{Aplikasi bioinsektisida}

Bioinsektisida yang telah diformulasikan di atas diencerkan dengan menggunakan 11 air steril untuk $1 \mathrm{~kg}$ bioinsektisida. Larutan tersebut selanjutnya disaring menggunakan kain kasa berpori $0,1 \mathrm{~mm}$ dan diambil sebanyak $100 \mathrm{ml}$ dengan kerapatan $1 \times 10^{6}$ konidia $/ \mathrm{ml}$ untuk diaplikasikan pada serangga uji. Aplikasi dilakukan dengan cara menyemprotkan secara langsung bioinsektisida pada tanaman pepaya yang telah dihuni 30 ekor nimfa $P$. marginatus setiap hari hingga nimfa menjadi imago, kemudian dihitung jumlah nimfa yang mati. Percobaan ini diulang 10 kali.

\section{Pengamatan viabilitas konidia}

Pengamatan viabilitas konidia dilakukan dengan cara suspensi setiap formulasi (100 g bioinsektisida dilarutkan dalam $100 \mathrm{ml}$ air steril) diambil $10 \mathrm{ml}$ dan dimasukan ke dalam tabung reaksi dan diinkubasikan selama 24 jam dan 48 jam. Setelah 24 jam suspensi diambil $1 \mathrm{ml}$ untuk 
diamati viabilitasnya. Viabilitas konidia dihitung berdasarkan perbandingan jumlah konidia yang berkecambah dari 100 konidia total yang diamati di bawah mikroskop. Bioinsektisida yang digunakan dalam pengujian viabilitas ini berumur simpan 3 bulan pada suhu ruangan.

\section{Analisis data}

Perbedaan data mortalitas nimfa, nilai $\mathrm{LT}_{50}$, serta viabilitas konidia antar perlakuan dianalisis menggunakan ANOVA dan uji lanjut BNJ 5\%. Lethal Time $\left(\mathrm{LT}_{50}\right)$ dianalisis menggunakan analisis probit yang semua penghitungan dibantu dengan program SPSS 16.

\section{HASIL}

\section{Mortalitas Paracoccus marginatus}

Mortalitas nimfa $P$. marginatus tertinggi $(82,86 \%)$ terjadi pada formulasi dengan bahan pembawa kompos yang diperkaya $T$. virens, tetapi tidak berbeda nyata dengan bahan pembawa campuran dedak dan serbuk kayu $(79,52 \%)$ dan serbuk kayu (78,57\%). Mortalitas nimfa terendah $(73,48 \%)$ ditemukan pada formulasi dengan bahan pembawa abu sekam dan berbeda nyata dengan perlakuan lainnya (Tabel 1). Mortalitas nimfa P. marginatus pada kontrol 1 rata-rata $29,52 \%$, sedangkan pada kontrol 2 rata-rata $75,71 \%$.

Mortalitas nimfa P. marginatus pada formulasi dengan bahan pembawa kompos kering maupun kompos kadar air normal tidak menunjukkan perbedaan yang nyata. Di antara semua bahan pembawa pada penelitian ini, bahan pembawa kompos yang diperkaya dengan $T$. virens menunjukkan hasil terbaik. Hal ini karena memiliki kemampuan mempertahankan keefektifan dan meningkatkan kemampuan mematikan serangga uji $(82,86 \%)$ tertinggi bila dibandingkan dengan bahan pembawa lainnya atau bila dibandingkan dengan konidia yang masih berbentuk isolat (75,71\%) (Tabel 1).

\section{$\mathbf{L T}_{50}$, viabilitas konidia, dan gejala infeksi} Beauveria bassiana

$\mathrm{LT}_{50}$ bioinsektisida tersingkat ditemukan pada formulasi dengan bahan pembawa kompos diperkaya $T$. virens (3,55 hari) dan dedak (3,56 hari). $\mathrm{LT}_{50}$ bioinsektisida terlama $(3,73$ hari) ditemukan pada formulasi dengan bahan pembawa abu sekam (Tabel 2). Saat kondisi tanpa bioinsektisida (kontrol 1) lama hidup nimfa P. marginatus lebih dari 6 hari (6,55 hari). $\mathrm{LT}_{50}$ isolat $B$. bassiana rata-rata 3,67 hari lebih lama bila dibandingkan pada formulasi dengan bahan pembawa kompos diperkaya $T$. virens dan dedak. Hal ini menunjukkan formulasi bioinsektisida dengan bahan pembawa kompos diperkaya $T$. virens atau dedak dapat mempersingkat waktu kematian 50\% serangga uji.

Viabilitas konidia $B$. bassiana pada kontrol 2 (isolat $B$. bassiana) tertinggi baik pada umur suspensi 24 jam (46,33\%) maupun 48 jam (44,79\%) (Tabel 3). Pada suspensi umur 24 jam dan 48 jam, viabilitas konidia kontrol 2 tersebut tidak berbeda nyata dengan formulasi dedak, dedak campuran serbuk kayu, dan kompos diperkaya T. virens. Viabilitas konidia pada formulasi kompos kering, kompos, abu sekam, dan serbuk kayu menurun signifikan dibandingkan formulasi dedak, dedak campuran serbuk kayu, dan kompos diperkaya

Tabel 1. Mortalitas nimfa Paracoccus marginatus yang diaplikasikan bioinsektisida berbahan aktif konidia Beauveria bassiana

\begin{tabular}{lc}
\hline Bahan pembawa formulasi & Mortalitas $(\%) \mathrm{X} \pm \mathrm{SD}$ \\
\hline Kompos kering & $76,19 \pm 6,51 \mathrm{c}$ \\
Kompos & $77,14 \pm 6,51 \mathrm{~cd}$ \\
Abu sekam & $73,48 \pm 6,87 \mathrm{~b}$ \\
Dedak & $78,10 \pm 7,16 \mathrm{~d}$ \\
Serbuk kayu & $78,57 \pm 11,68 \mathrm{de}$ \\
Dedak dan serbuk kayu & $79,52 \pm 5,59 \mathrm{e}$ \\
Kompos diperkaya $T$. virens & $82,86 \pm 4,88 \mathrm{f}$ \\
Air steril (kontrol 1) & $29,52 \pm 6,21 \mathrm{a}$ \\
Isolat (kontrol 2) & $75,71 \pm 9,76 \mathrm{c}$ \\
\hline
\end{tabular}

Angka yang diikuti oleh huruf yang sama tidak berbeda nyata pada BNJ 5\%

Tabel 2. Nilai $\mathrm{LT}_{50}$ bioinsektisida yang diaplikasikan pada serangga uji Paracoccus marginatus

\begin{tabular}{lccc}
\hline \multirow{2}{*}{$\begin{array}{l}\text { Bahan pembawa } \\
\text { formulasi }\end{array}$} & \multirow{2}{*}{$\mathrm{LT}_{50}$} & \multicolumn{2}{c}{ Selang } \\
& (Hari) & kepercayaan (95\%) \\
\cline { 2 - 4 } & Tercepat & Terlama \\
\hline Kompos kering & 3,71 & 3,50 & 3,97 \\
Kompos & 3,72 & 3,49 & 4,01 \\
Abu sekam & 3,73 & 3,51 & 4,00 \\
Dedak & 3,56 & 3,33 & 3,86 \\
Serbuk kayu & 3,70 & 3,47 & 3,99 \\
Dedak dan serbuk kayu & 3,62 & 3,39 & 3,93 \\
Kompos diperkaya T. virens & 3,55 & 3,32 & 3,84 \\
Air steril (kontrol 1) & - & - & - \\
Isolat (kontrol 2) & 3,67 & 3,46 & 3,94 \\
\hline
\end{tabular}


Tabel 3. Viabilitas konidia Beauveria bassiana pada bioinsektisida dengan berbagai bahan pembawa

\begin{tabular}{lcc}
\hline \multirow{2}{*}{ Bahan pembawa formulasi } & \multicolumn{2}{c}{ Rata-rata viabilitas konidia (\%) } \\
\cline { 2 - 3 } Kompos kering & Umur suspensi 24 jam & Umur suspensi 48 jam \\
Kompos & $24,93 \mathrm{a}$ & $24,79 \mathrm{a}$ \\
Abu sekam & $20,19 \mathrm{a}$ & $24,26 \mathrm{a}$ \\
Dedak & $29,39 \mathrm{ab}$ & $26,19 \mathrm{a}$ \\
Serbuk kayu & $41,13 \mathrm{c}$ & $36,33 \mathrm{~b}$ \\
Dedak dan serbuk kayu & $19,59 \mathrm{a}$ & $18,33 \mathrm{a}$ \\
Kompos diperkaya $T$. virens & $41,06 \mathrm{c}$ & $37,53 \mathrm{~b}$ \\
Air steril (kontrol 1) & $36,93 \mathrm{bc}$ & $38,66 \mathrm{~b}$ \\
Isolat (kontrol 2) & - & - \\
\hline Anka & $46,33 \mathrm{c}$ & $44,79 \mathrm{~b}$
\end{tabular}

Angka yang diikuti oleh huruf yang sama pada lajur yang sama tidak berbeda nyata pada BNJ 5\%

T. virens. Dengan demikian, formulasi dedak, dedak campuran serbuk kayu, dan kompos diperkaya T. virens lebih baik dibandingkan formulasi kompos kering, kompos, abu sekam, dan serbuk kayu dalam mempertahankan viabilitas konidia $B$. bassiana.

Nimfa $P$. marginatus yang terinfeksi konidia $B$. bassiana menunjukkan gejala yang mirip seperti pada serangga lainnya yang terinfeksi cendawan tersebut. Nimfa setelah diaplikasikan bioinsektisida menunjukkan gejala kurang nafsu makan dan kurang mampu menempel pada daun pepaya karena stiletnya tidak ditusukkan ke jaringan tanaman akibatnya nimfa sakit akan jatuh. Jatuhnya nimfa tersebut menunjukkan bahwa nimfa sakit tidak makan karena stiletnya tidak lekat di jaringan tanaman. Nimfa yang terinfeksi akan mengering dengan bagian luar ditumbuhi hifa cendawan berwarna putih, sedangkan tubuh nimfa itu sendiri menunjukkan warna hitam keputihan (Gambar 3). Ciri-ciri lainnya nimfa sakit tersebut tidak mengeluarkan bau busuk seperti gejala terinfeksi bakteri. Gejala yang sama juga pernah dilaporkan Herlinda et al. (2006b) pada ulat kubis (Plutella xylostella) yang terinfeksi B. bassiana.

Dari serangga yang terinfeksi setelah aplikasi bioinsektisida, kemudian diisolasi cendawan yang menempel dan menunjukkan pada biakan agar tumbuh cendawan yang koloninya berwarna putih (Gambar 4). Konidia cendawan tersebut berbentuk bulat. Ciri-ciri tersebut menunjukkan ciri-ciri $B$. bassiana. Dengan demikian, cendawan yang menginfeksi dan menyebabkan kematian pada $P$. marginatus adalah $B$. bassiana.

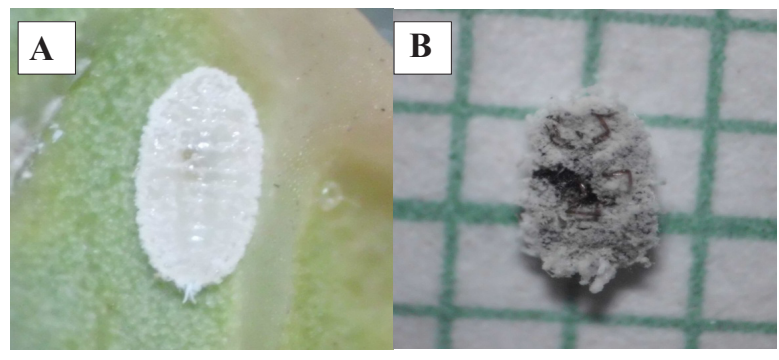

Gambar 3. Morfologi nimfa Paracoccus marginatus. A: sehat; dan B: sakit.

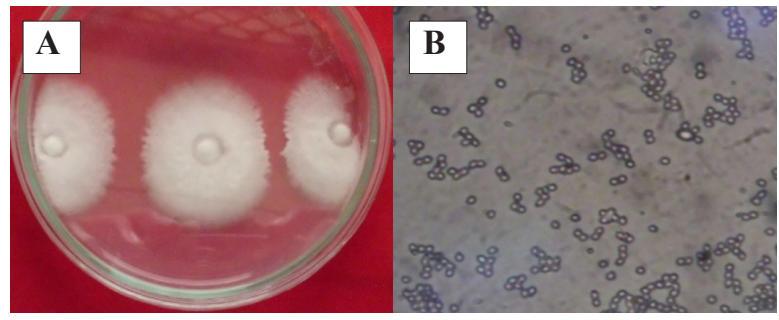

Gambar 4. Beauveria bassiana. A: serangga yang terinfeksi pada media GYA; dan B: mikroskopis konidia B. bassiana.

\section{PEMBAHASAN}

Tingginya mortalitas bioinsektisida dengan bahan pembawa kompos yang diperkaya $T$. virens disebabkan peran dari cendawan tersebut dalam membantukerja B. bassiana. Data hasil pengamatan yang belum penulis publikasikan menunjukkan T. virens mampu membunuh nimfa Lipaphis erysimi hingga mortalitas mencapai $60-70 \%$. Dari pengamatan uji invitro pada medium agar juga menunjukkan bahwa $T$. virens dan $B$. bassiana dapat hidup bersama tanpa saling menghambat pada satu cawan petri. Dengan demikian, keberadaan $T$. virens pada bahan pembawa bioinsektisida pada penelitian ini tidak menghambat kehidupan konidia $B$. bassiana dan bahkan dapat bersinergis dalam membunuh serangga inangnya. 
Lebih rendahnya mortalitas yang ditimbulkan oleh bioinsektisida dengan bahan pembawa abu sekam disebabkan abu sekam kurang mampu mempertahankan persistensi konidia $B$. bassiana. Abu sekam bersifat menyerap air sehingga dapat menyebabkan konidia cendawan kering dan bila terlalu kering dapat menyebabkan konidia cendawan menurun viabilitasnya. Hasyim (2006) menyatakan bahwa bahan pembawa berbentuk abu kurang mampu mempertahankan keefektifan dan persistensi cendawan entomopatogen bila dibandingkan bahan pembawa lainnya (tepung jagung dan beras). Pada penelitian ini, bioinsektisida dengan bahan pembawa kompos kering dan kompos berkadar air normal cukup baik untuk menjadi bahan pembawa, bioinsektisida dengan bahan pembawa kompos memiliki keuntungan selain dapat mengendalikan hama sekaligus komposnya dapat menyuburkan tanaman.

Lama hidup nimfa $P$. marginatus yang diaplikasikan bioinsektisida pada penelitian ini lebih singkat dibandingkan kontrol air tanpa aplikasi bioinsektisida sehingga nimfa tidak mencapai fase imago. Tanpa aplikasi bioinsektisida $P$. marginatus dapat mencapai fase imago dan mampu berbiak sehingga populasi dapat bertambah. Serangga uji yang diaplikasikan bioinsektisida menghasilkan $\mathrm{LT}_{50}$ sebesar 3-4 hari. Toledo et al. (2010) mendapat kecenderungan yang sama karena cendawan butuh waktu untuk berkecambah, mulai dari perkecambahan konidia membutuhkan 24-48 jam, setelah 72 jam tabung kecambah sudah dapat ditemukan pada kutikula integumen serangga inang tersebut.

$\mathrm{LT}_{50}$ pada aplikasi bioinsektisida dengan bahan pembawa kompos diperkaya $T$. virens paling singkat. Hal ini disebabkan konidia $B$. bassiana pada perlakuan tersebut dipercepat kemampuan membunuhnya karena ada $T$. virens yang bersinergis dalam membunuh nimfa $P$. marginatus. Lamanya $\mathrm{LT}_{50}$ pada aplikasi bioinsektisida dengan bahan pembawa abu sekam disebabkan abu sekam bersifat menyerap air yang dapat menyebabkan konidia $B$. bassiana kering dan menurun viabilitasnya. Data hasil pengamatan viabilitas konidia bioinsektisida pada penelitian ini rata-rata hanya $29,39 \%$, sedangkan viabilitas konidia $B$. bassiana pada bioinsektisida dengan bahan pembawa kompos diperkaya $T$. virens ratarata $36,93 \%$.

Nimfa $P$. marginatus yang terinfeksi konidia $B$. bassiana menunjukkan gejala yang mirip seperti pada serangga lainnya yang terinfeksi cendawan tersebut. Hasil pengamatan Herlinda et al. (2008b) pada walang sangit menunjukkan gejala awal serangga terinfeksi cendawan entomopatogen terlihat dari kurangnya kemampuan makan dan mobilitasnya. Apabila hifa sudah berkembang di dalam tubuh serangga, maka miselia dan konidia akan muncul keluar permukaan tubuh serangga, seperti yang ditemukan pada penelitian ini.

Dari hasil penelitian ini, P. marginatus yang mati karena aplikasi bioinsektisida diisolasi konidianya, lalu dimurnikan pada media GYA. Dari hasil isolasi tersebut terlihat koloni $B$. bassiana yang ada di dalam cawan petri berwarna putih, sedangkan hasil pengamatan di bawah mikroskop konidia cendawan tersebut berbentuk bulat. Ciri-ciri tersebut merupakan ciri yang dimiliki oleh B. bassiana.

\section{KESIMPULAN}

Semua bioinsektisida yang berbahan aktif konidia $B$. bassiana efektif membunuh nimfa $P$. marginatus. Bioinsektisida yang paling efektif ialah bioinsektisida dengan bahan pembawa kompos yang mengandung cendawan $T$. virens yang mampu membunuh $82,86 \%$ nimfa $P$. marginatus dengan $\mathrm{LT}_{50}$ rata-rata hanya 3,55 hari. Bioinsektisida yang paling rendah menyebabkan mortalitas P. marginatus $(73,48 \%)$ ialah bioinsektisida dengan bahan pembawa abu sekam dan $\mathrm{LT}_{50}$ rata-rata 3,73 hari.

\section{UCAPAN TERIMA KASIH}

Penelitian ini bagian dari Riset Dasar pada Program Insentif yang dibiayai oleh Kementerian Negara Riset dan Teknologi, sesuai dengan Surat Perjanjian Pelaksanaan Program Insentif Tahun Anggaran 2011, Nomor: 1.49.03/SEK/IR/ PPK/I/2011, Tanggal 17 Januari 2011 yang diketua oleh Siti Herlinda. 


\section{DAFTAR PUSTAKA}

Friamsa N. 2009. Biologi dan Statistik Demografi Kutu putih Pepaya, Paracoccus marginatus Williams \& Granara de Willink (Hemiptera: Pseudococcidae) pada Tanaman Pepaya (Carica papaya L). Skripsi. Bogor: Institut Pertanian Bogor.

Feng MG, Poprowski TJ, Khachatourians GG. 1994. Production, formulation, and application of the entomopathogenic fungus Beauveria bassiana for insect control: current status. Biocontrol Science and Technology 4:30-34. http://dx.doi. org/10.1080/09583159409355309.

Hasyim A. 2006. Evaluasi bahan carrier dalam pemanfaatan jamur entomopatogen, Beauveria bassiana (Balsamo) Vuillemin untuk mengendalikan hama penggerek bonggol pisang, Cosmopolites sordidus Germar. Hortikultura 16:190-198.

Herlinda S. 2010. Spore density and viability of entomopathogenic fungal isolates from Indonesia, and its virulence against Aphis gossypii Glover Homoptera: Aphididae). Tropical Life Sciences Research 21:13-21.

Herlinda S, Irsan C, Mayasari R, Septariani S. 2010. Identification and selection of entomopathogenic fungi as biocontrol agents for Aphis gossypii from South Sumatra. Microbiology Indonesia 4:137142. http://dx.doi.org/10.5454/mi.4.3.7.

Herlinda S, Mulyati SI, Suwandi. 2008a. Jamur entomopatogen untuk mengendalikan wereng coklat pada tanaman padi. Agritrop 27:119-126.

Herlinda S, Mulyati SI, Suwandi. 2008b. Selection of isolates of entomopathogenic fungi, and the bioefficacy of their liquid production against Leptocorisa oratorius Fabricius nymphs. Microbiology Indonesia 2:141-145.

Herlinda S, Hamadiyah, Adam T, Thalib R. 2006a. Toksisitas isolat-isolat Beauveria bassiana (Bals.) Vuill. terhadap nimfa Eurydema pulchrum
(Westw.) (Hemiptera: Pentatomidae). Agria 2:3437.

Herlinda S, Utama MD, Pujiastuti Y, Suwandi. 2006b. Kerapatan dan viabilitas spora Beauveria bassiana (Bals.) Vuill. akibat subkultur dan pengayaan media, serta virulensinya terhadap larva Plutella xylostella (Linn.). Jurnal Hama Penyakit Tanaman Tropika 6:70-78.

Nunilahwati H, Herlinda S, Irsan C, Pujiastuti. 2012. Eksplorasi, isolasi, dan seleksi jamur entomopatogen Plutella xylostella (Lepidoptera: Yponomeutidae) pada tanaman caisin (Brassica chinensis) di Sumatera Selatan. Jurnal Hama Penyakit Tanaman Tropika 12:1-11.

Rauf A. 2009. Pest Risk Analysis: Paracoccus marginatus. Bogor: Departemen Proteksi Tanaman. Fakultas Pertanian IPB.

Suwandi. 2004. Effectiveness of shrimps shell compost extract for suppression of leaf diseases on cowpea, chili pepper and cabbage. Pest Tropical Journal 1:18-25.

Trizelia. 2008. Patogenitas cendawan cntomopatogen Nomuraea rileyi (Farl.) Sams. terhadap hama Spodoptera exigua Hübner (Lepidoptera: Noctuidae). Jurnal Entomologi Indonesia 5:108-115.

Trizelia, Syahrawati MY, Mardiah A. 2011. Patogenisitas Beberapa Isolat Cendawan Entomopatogen Metarhizium spp. terhadap Telur Spodoptera litura Fabricius (Lepidoptera: Noctuidae). Jurnal Entomologi Indonesia 8:4554

Toledo AV, Remes Lenicov AMM, López Lastra CC. 2010. Histopathology caused by the entomopathogenic fungi, Beauveria bassiana and Metarhizium anisopliae, in the adult planthopper, Peregrinus maidis, a maize virus vector. Journal of Insect Science 10:1-10 Available at: insectsicence.org/10.35 [accessed 24 September 2010]. http://dx.doi.org/10.1673/031.010.3501. 